\title{
Representation of locomotor space by the blind
}

\author{
C. VERAART and M.-C. WANET-DEFALQUE \\ Laboratoire de Neurophysiologie, University of Louvain, Brussels, Belgium
}

\begin{abstract}
Representation of locomotor space by early- and late-blind subjects and by blindfolded sighted subjects was studied within a perimeter where the direction and distance of landmarks had to be located. Subjects were guided along routes to be explored, both with and without the use of an ultrasonic echolocating prosthesis that enabled object localization. Without the prosthesis, early-blind subjects' performance was worse than that of visually experienced subjects, both in direction and in distance assessments. With the help of the prosthesis, early-and late-blind subjects' performance improved, especially in distance assessments; late-blinds' performance remained better than that of early-blinds. These results suggest that early-blinds' spatial representation would be the most impaired on routes requiring the mastering of euclidean concepts.
\end{abstract}

Blindness greatly impairs people's ability to move safely and to maintain their orientation toward a goal. Foulke (1982) noted that blind pedestrians lack the foresight necessary to program safe movements. Rieser, Guth, and Hill (1982) concluded that good spatial orientation depends on three component processes: knowing the spatial layout of a locale, updating one's position within a locale, and applying systems of spatial concepts to calculate routes within a locale. The mastery of the first two components in an unfamiliar area depends on the amount of spatial information gained when traveling within that area. Obviously, vision plays a major role in the acquisition of this spatial information (Foulke, 1982; Gibson, 1958; Jansson, 1983; Millar, 1981), and lack of vision specifically impairs this acquisition.

Locomotor performance of blind people depends on many factors, one of which is visual experience. Early visual experience seems to give some advantage: Indeed, in various spatial orientation tasks (Byrne \& Salter, 1983; Herman, Chatman, \& Roth, 1983; Rieser, Lockman, \& Pick, 1980), early-blind subjects (i.e., subjects who lost their vision early in life) perform generally less well than late-blind or blindfolded sighted subjects. Moreover, the ability to use spatial concepts seems to be impaired in early-blind subjects (Fletcher, 1981; Hartlage, 1976; Hatwell, 1966; Stephens \& Grube, 1982).

During the past 30 years, some technical aids have been designed to increase remote space perception by blind people. The long cane (Hoover, 1950) and the guide dog (Warnath \& Seyfarth, 1982) are well-known examples.

\footnotetext{
Part of this work was done with the help of C. Mehauden. The authors wish to thank C. Schepens (Ligue Braille, Belgium) and all the subjects who took part in the experiment. We are indebted to J. Crémieux for his helpful criticism of this manuscript. We are also grateful to M. Meulders and to the staff of the laboratory, especially to C. Klepper for secretarial assistance and to P. Dubrulle for technical skill. This study was partially supported by a grant from the Ministère de la Communauté Française, Affaires sociales, Belgique.

Please address all correspondence to either of the authors at the Laboratoire de Neurophysiologie, U.C.L.54.49, Avenue Hippocrate, 54, B-1200 Brussels, Belgium.
}

Furthermore, since the 1960 s, electronic travel aids have increased the distance at which blind people can become aware of an obstacle. Examples of these are the electronic torch and the laser cane (Farmer, 1978) and the binaural sensory aid (Kay, 1974).

Many studies have measured subjects' performance with these aids and have evaluated the improvement in blind pedestrians' safety (Shingledecker, 1983; Shingledecker \& Foulke, 1978; Gillipsie \& De l'Aune, 1974). The effects of these electronic travel aids on spatial orientation, however, have not yet been studied.

The present study had two major goals. The first goal was to evaluate further the influence of early visual experience on spatial orientation. Most studies that use spaces unfamiliar to subjects focus either on the distance parameter or on the direction parameter; we decided to combine these two parameters in one task to study the ability of blind subjects to locate, with respect to their own positions, the landmarks in a given perimeter. We examined the influence of early visual experience on the accuracy of this representation by comparing the performance of early-blind, late-blind, and blindfolded sighted subjects in this task. The second goal was to ascertain whether an electronic travel aid, similar to Kay's (1974) binaural sensory aid, could modify the spatial representation that a blind traveler develops while walking. Accordingly, we trained subjects in the use of this electronic travel aid and then tested the subjects' performance on the same task while they used the aid. The results for both distance and direction assessments were compared with those obtained without the travel aid.

\section{METHOD}

Sixteen subjects, aged 21 to 54 years, participated in the experiment; 3 were early blind (had become blind early in life), three were late blind (had become blind later in life), and 10 were blindfolded sighted subjects (the controls). Table 1 summarizes the blind subjects' characteristics. All of these blind participants were longcane users and, except for Subjects V.E. and F.R., were independent travelers; none of them had used an electronic travel aid. 
Table 1

Characteristics of the Blind Subjects

\begin{tabular}{|c|c|c|c|c|c|}
\hline Subject & Sex & $\begin{array}{l}\text { Age at Test } \\
\text { (Years) }\end{array}$ & $\begin{array}{c}\text { Age at Onset } \\
\text { (Years) }\end{array}$ & Etiology & $\begin{array}{c}\text { Residual } \\
\text { Vision }\end{array}$ \\
\hline \multicolumn{6}{|c|}{ Early-Blinds } \\
\hline J.F. & $\mathbf{M}$ & 21 & Congenital & Retinal degeneration & - \\
\hline P.I. & $\mathbf{M}$ & 54 & $3 ?$ & $\begin{array}{l}\text { Marfan's syndrome, or pigmen- } \\
\text { tary retinopathy and cataract }\end{array}$ & - \\
\hline V.E. & $\mathbf{F}$ & 25 & Congenital & Tapetoretinal degeneration & $\begin{array}{l}\text { Light } \\
\text { perception }\end{array}$ \\
\hline \multicolumn{6}{|c|}{ Late-Blinds } \\
\hline C.R. & $\mathbf{F}$ & 36 & 10 & Pigmentary retinopathy & $\begin{array}{l}\text { Light } \\
\text { perception }\end{array}$ \\
\hline F.R. & $\mathbf{M}$ & 30 & 28 & Trauma & - \\
\hline J.J. & $\mathbf{M}$ & 23 & 21 & Trauma & 一 \\
\hline
\end{tabular}

Before the experiment began, the blind subjects were trained to use the prosthesis. This ultrasonic echolocating device, roughly similar to the binaural sensory aid (Kay, 1974), includes a pair of spectacles equipped with three ultrasonic transducers and two earphones. The first transducer emits ultrasounds in the air in a cone of about $70^{\circ}$; echoes reflected by obstacles are received by the two other transducers, which work as microphones. An electronic case, connected to the spectacles and containing the battery power supply, emits the signals and processes echoes by decoding them into audible sounds sent to the user's earphones. The distance to obstacles is proportional to the pitch of the sound (slope $=1800 \mathrm{~Hz} / \mathrm{m}$ ); the direction is coded by binaural intensity balance. A pole (diameter $=9 \mathrm{~cm}$; length $=2 \mathrm{~m}$ ) could be detected at about $3 \mathrm{~m}$; a broad obstacle, such as a wall, could be detected at up to $6 \mathrm{~m}$, the related frequency being about $10.8 \mathrm{kHz}$ (Ciselet, Pequet, Richard, Veraart, \& Meulders, 1982).

The learning program comprised six 50 -min sessions, distributed over a 3- to 4-week span and performed in various inside and outside environments. The first sessions, occurring inside a quiet, large room $(7 \times 18 \mathrm{~m})$, involved the localization of easily detectable objects, such as poles, walls, windows, and so forth. Then the subject had to coordinate his or her motor behavior with the spatial information provided by the prosthesis: For example, the subject progressively learned to walk parallel to a row of poles, to detect the location of a door in a wall, to grasp an object, and so forth. Finally, the subject learned a route inside a building and one outside, in a residential area. At the end of each session, the success of the lesson was evaluated. This training program followed a procedure similar to that used by others with electronic travel aids (Hornby, Kay, Satherly, \& Kay, 1985). Furthermore, we assessed improvements in the use of the prosthesis during the learning period. For this purpose, we measured the subjects' performance as they crossed a large circular field of about $80 \mathrm{~m}^{2}$, occupied by 16 randomly positioned poles; their performance was tested three times, twice during training and once just afterward. The mean performance of the subjects increased over time (Veraart \& Wanet, 1985).

The present experiment was performed inside the same large room used for the first sessions in the training program. The room was nondescript: a cement floor, plastered walls, and a concrete ceiling. During the experiment, only the subject and one experimenter were present.

The subjects had to follow six simple routes defined inside an area of about $40 \mathrm{~m}^{2}$ and including landmarks the location of which they had to remember. These routes were defined by various objects (poles, panels, cupboards, shelves, walls, tables, etc.); similar objects had been used during training with the echolocating prosthesis. Each route measured about $5 \mathrm{~m}$, included one to four turns (see Figure 1), and contained three landmarks: the starting point, the goal point, and an intermediate point. These three landmarks comprised portions of the objects defining the routes and were situated at the level of the subject's head (e.g., corner of a cupboard, edge of a panel, etc.). On a given route, the starting point and the intermediate point were identified by very different landmarks.

The starting point of all routes (except $A B C$ ) was the goal point of the preceding one (e.g., after ABC, the next route was CDE). To test whether the subjects would refer to a euclidean representation of space in their distance estimations, the task was divided into two kinds of situations. Three of the six routes were drawn in such a way that the goal point was nearer to the starting point than to the intermediate landmark (i.e., Routes ABC, EFG, and KLM in Figure 1); these were classified as the "Euc" routes. This situation required that the subjects use a more or less euclidean spatial representation by taking into account both the spatial consequences

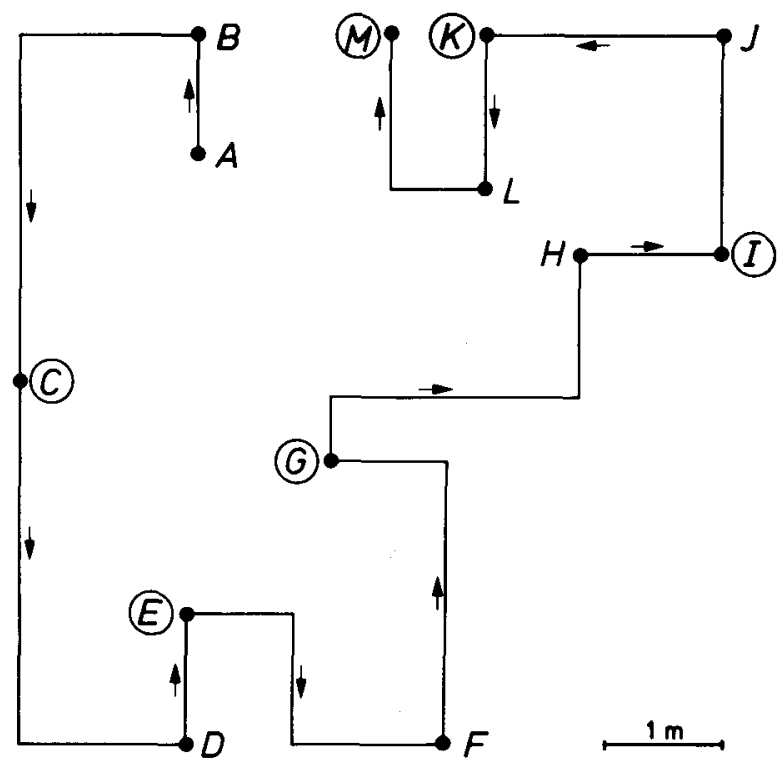

Figure 1. Outline of the experimental setup. Six routes were designed, each one comprising two landmarks and one viewpoint. The landmarks are labeled by letters; in addition, the six viewpoints are circled. Routes were in the directions shown. As an example, in Route ABC, $A$ and $B$ were the landmarks to be localized from Viewpoint $C$; in Route $C D E, C$ and $D$ were landmarks and $E$ the viewpoint, and so forth. 
of their direction changes and the distances covered. The three other routes, the "non-Euc" routes, presented the landmarks in such a way that the temporal sequences of encountered landmarks reflected the order of spatial remoteness from the starting points. Accordingly, a functional spatial representation, that is, knowledge of the walking distance between landmarks (Rieser et al., 1980), is sufficient for success on these non-Euc routes. Of course, all the routes differed one from another; in addition to their classification into Euc and non-Euc, other peculiarities characterized each individual route. We attempted to distribute equally such characteristics (number of turns, objects defining the routes or the landmarks, separation in distance and in direction between the two landmarks, etc.) between these two kinds of routes.

In the first experimental condition, the subjects held an experimenter's arm and followed him/her twice successively along a given route (say, $A B C$ ). The subjects touched all objects encountered, and the experimenter named these objects. Each time the subjects faced one of the three landmarks along a route, they were told, "This is the starting point," "This is the intermediate point," or "This is the goal point." After the first exploration of the route, and in preparation for the second, the subjects were guided to the starting point of the same route along a random path. Then, standing at the goal point (C), the subjects were asked to infer the straightline distance between their position and each landmark (A and B) and the directions of these two landmarks. Distance was recorded relatively: At $C$, the correct answer was "A is nearer than B." The response was marked 0 if true and 1 if false. Subjects indicated direction by turning their bodies in the presumed direction; thus, for a perfect answer, the landmark located by the subjects would be situated in their median plane. The angle between a subject's estimate and the actual direction of a landmark constituted the angular error. The angular error was assessed by drawing a line on the floor to indicate the direction of the subject's median plane and then measuring the angle between this line and the actual direction of the landmark. For each route, two directional errors (one for each of the two landmarks) were thus recorded, as opposed to the single distance error.

In the second experimental condition, the blind subjects, trained according to the learning program and using the ultrasonic echolocating device, were also guided by an experimenter twice successively along a given route (Figure 1), but they were not allowed to touch any object. At the goal point, and still wearing the echolocating device, they had to locate the two landmarks in direction and distance, as in the first experimental condition. Signals produced by the ultrasonic echolocating device generally did not help the subject to locate the landmarks at this time: Either the range of the device was too limited to detect thin landmarks, or these landmarks could be confused with other objects along a route involving turns.

Before the experiment had begun, the subjects were trained to perform the task for similar routes; the subjects were given feedback about the accuracy of their responses both for direction and distance. Furthermore, during the initial training with the ultrasonic echolocating device, the subjects frequently were required to evaluate the relative distances or directions of objects.

Both experimental conditions were presented during two separate daily sessions, about 4 days apart. Although the subjects had been trained to perform the task (which involved a steady level of performance in both sessions), we tried to control the order of the experimental conditions. Accordingly, 1 early-blind and 2 late-blind subjects were first tested in the guided condition, whereas the other 3 subjects were first tested with the prosthesis. In the second session, the first route was chosen at random, and we hid the fact that the route design was identical in both sessions. Error scores for both distance and direction generally were averaged for the six routes for each subject. When a distinction was made between data on Euc and non-Euc routes, error scores were averaged for the three related routes.

\section{RESULTS}

\section{Early Visual Experience}

In the first experimental condition, the distance and direction scores of the 10 sighted subjects were compared with those of the 3 late-blind subjects and with those of the 3 early-blind subjects (see Figure 2).

To evaluate the influence of early visual experience on the spatial representation task, we performed a onedimensional analysis of variance on the three groups of subjects for both the distance and the direction scores. To be properly applicable to an analysis of variance, the discontinuous scale values of the distance estimates (error frequency) were transformed by the formula $\operatorname{arc} \sin \sqrt{p}$, where $p$ is the error frequency (D'Hainaut, 1975). It was found that the groups differed at a nearly significant level: $F=3.34(p<.07)$ for distance and $F=3.41(p<.06)$ for direction. We then decided to carry out a Student's $t$ test to see how these differences were organized. In the comparisons between the late-blind and the sighted subjects, the tests were two tailed; in the other comparisons, they were one tailed. In agreement with our hypothesis, the results confirmed the importance of early visual experience: Indeed, the early-blind group made significantly larger errors than the sighted group for both the distance $(t=2.58, p<.025)$ and the direction $(t=2.40, p<.025)$ assessments. Furthermore, the early-blind subjects also made significantly larger errors than the late-blind subjects on the direction estimates $(t=$ $2.30, p<.025$ ), but not on the distance estimates. As expected, the sighted and the late-blind groups did not significantly differ from each other, either for direction or for distance.

We also tested the hypothesis suggested by Rieser et al.'s (1980) work, namely, that early-blind people could build functional spatial representations more easily and more frequently than they could euclidean representations, unlike sighted and late-blind people, who are more often able to build euclidean spatial representations. Accordingly, for each group of subjects, we compared the distance estimates for the Euc routes with those for the nonEuc routes. For the early-blind group, we expected poorer performance on Euc routes than on non-Euc routes. Actually, the related performance was exactly the same: $55.6 \%$ (see Table 2). In fact, in our experimental conditions, the early-blind group evaluated relative distances poorly, as reflected by their mean performance levels near $50 \%$ whatever the kind of route considered. Finally, for the late-blind as well as for the sighted subjects, no significant performance differences on these two kinds of routes were observed.

\section{Influence of the Use of the Ultrasonic \\ Echolocating Prosthesis}

We computed the distance and direction scores of the 3 early-blinds and the 3 late-blinds in the second experimental condition (in which the prosthesis was used). Figure 3 compares these data with the scores obtained in 

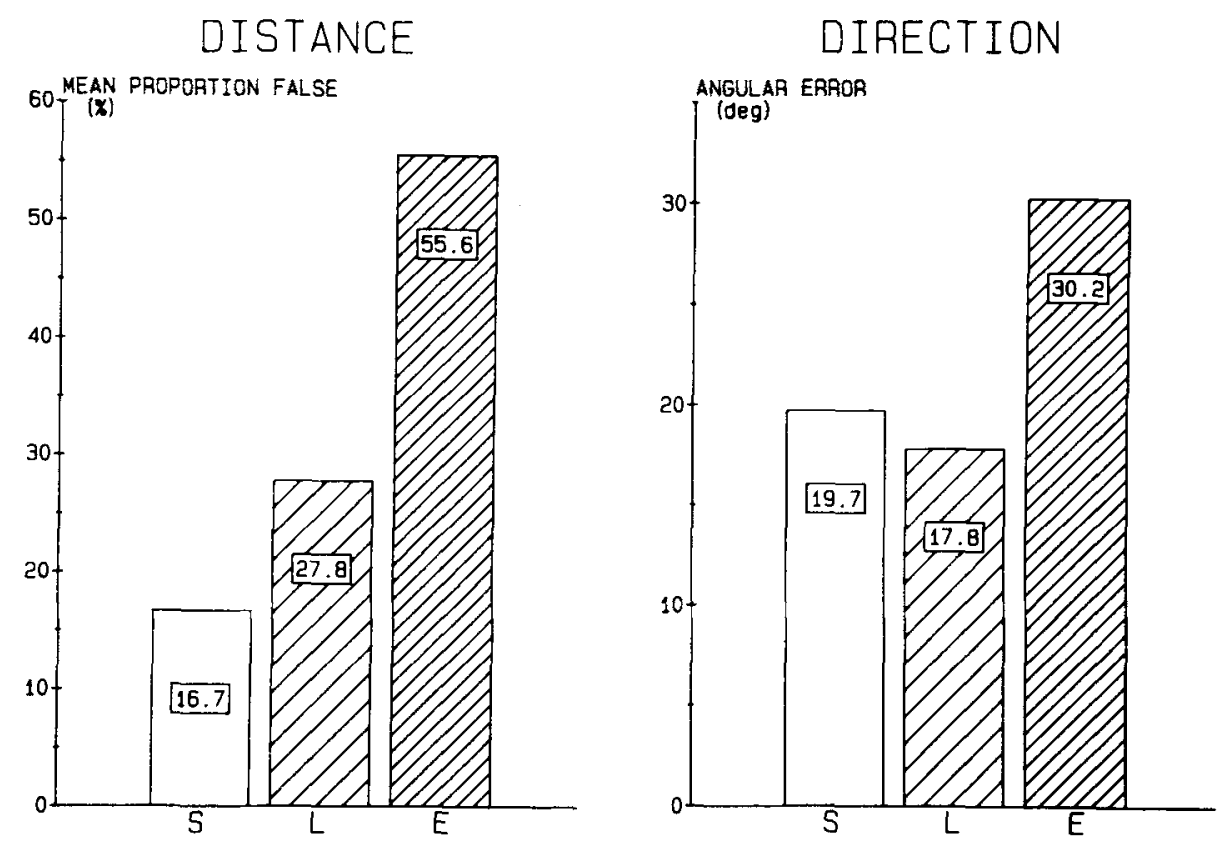

Figure 2. Mean errors in estimation of distance and direction during landmark localization by three groups of subjects guided in the locomotor space. $S=$ blindfolded sighted subjects; $L=$ late-blind subjects; $\mathbf{E}=$ early-blind subjects.

the first experimental condition (in which the prosthesis was not used).

We computed matched-pairs comparisons on the basis of the scores obtained by each group of blind subjects, in the two experimental conditions, for distance and for direction. Results are given for one-tailed tests. For both groups, in direction, the $t$ test showed no significant differences, with the ultrasonic echolocating prosthesis yielding only a slight advantage. In distance, on the contrary, the early-blind group actually performed significantly better with the help of the prosthesis $(t=3.38, p<.05)$; for the late-blind group, the trend illustrated in Figure 3 was not significant. For distance estimates, we also separated the Euc situations from the non-Euc ones, and, in each group of subjects, we compared the corresponding results in the two experimental conditions. These data are summarized in Table 2.

For Euc routes, distance estimates made by the earlyblind subjects with the help of the prosthesis were better than those made without the prosthesis, but not significantly; for the late-blind subjects, a similar trend was observed. For non-Euc routes, early-blind subjects performed significantly better with the prosthesis $(t=3.58$, $p<.05$ ); the $t$ test was not applied in the late-blind group (too few pairs different from zero).

With respect to the only results recorded when the prosthesis was used, the late-blind subjects' performance remained better than that of the early-blind subjects in both direction and distance; in these latter estimates only, this trend was found to be significant $(t=2.23, p<.05)$. If Euc and non-Euc situations were considered separately
(Table 2), early-blinds estimated distances better for the non-Euc situations, but not significantly so.

\section{DISCUSSION}

Representation of the locomotor space was investigated as a function of visual experience by means of inferential responses; the influence of the use of an artificial obstacle sensor on this ability was also studied.

The ultrasonic echolocating prosthesis used in this work was intended to help blind pedestrians to localize, in distance and in direction, obstacles, while also providing very crude pattern-recognition cues. To master the auditory signals provided by this aid, blind volunteers had to follow an exacting training program. The restricted number of blind subjects in this study must be considered in relation to this requirement.

The accuracy of the spatial representation of a route has been evaluated by considering separately responses for both distance and direction. Other researchers have asked subjects to draw a map of the route (Dodds, Howarth, \& Carter, 1982). But, as stressed by Lepecq and Pêcheux (1984), such an alternative approach invokes processes that are specific to the drawing ability and that would interfere with the processes involved in spatial representation: When drawing, subjects have to use a specific code for the objects; they must translate a threedimensional perception into a two-dimensional representation, and they must perform scale transformations. Indeed, if the concept of "cognitive map" is widely used in the literature, its meaning is metaphoric. 

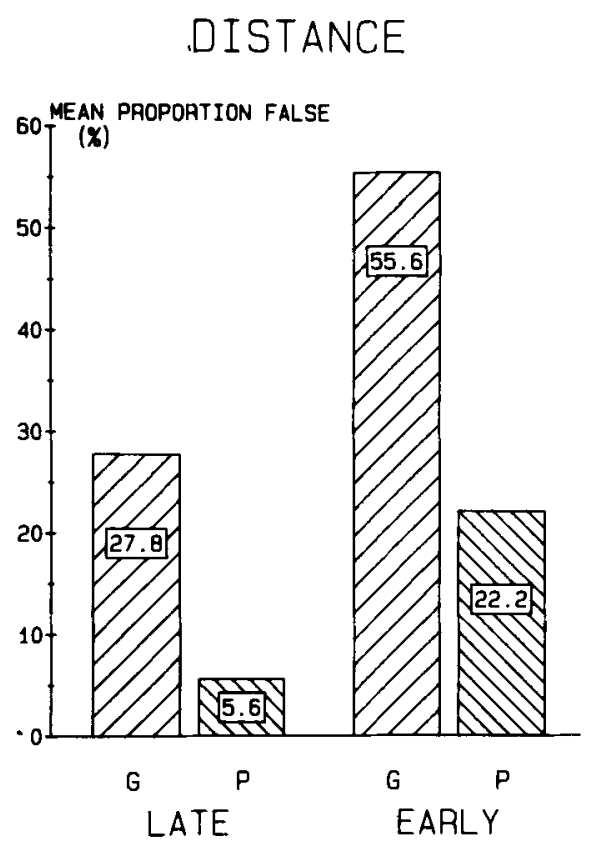

DIRECTION

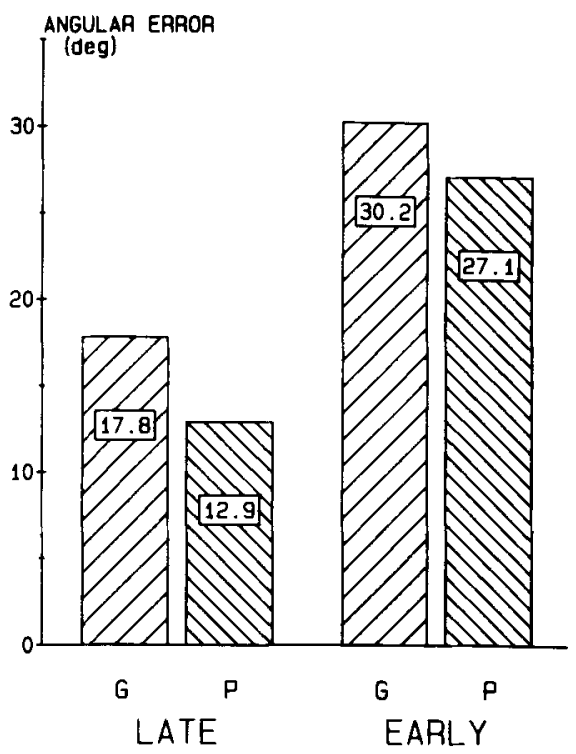

Figure 3. Mean errors in distance and in direction during landmark localization performed in the locomotor space by two groups of blind subjects using the ultrasonic echolocating prosthesis, in comparison with results obtained when these subjects were guided along the routes. $G$ = subjects' errors, without the prosthesis; $\mathbf{P}=$ subjects' errors with the prosthesis.

For distance estimation, we did not define a suitable motor response. Indeed, a response consisting of actually covering the predicted distance would suffer from various drawbacks. For example, if a wrong direction is taken, the subject could stumble against an object and thus would have to stop before completion of the motor response. In another instance, an obstacle could actually be interposed between the goal point and the distant landmark. To avoid these problems, a verbal response was required. Moreover, in order to avoid problems related to the variability and subjectivity of the unit of measurement, a relative estimation of distance was selected. $\mathrm{Ob}$ viously, this kind of response does not give a quantitative evaluation of distances, but it nevertheless reflects the subject's spatial representation; this response has also been selected in other studies of geographical space representation (Cauvin, 1984; Haber, 1985; Lockman, Rieser, \& Pick, 1981).

As far as directional estimations are concerned, an adequate motor response was easy to find. Body orientation toward the estimated landmark position was selected.

Table 2

Percentage of Error in Distance Estimates in the Two Experimental Conditions When Euc Routes Were Considered Separately From Non-Euc Routes

\begin{tabular}{lccccc} 
& \multicolumn{2}{c}{ Early-Blinds } & & \multicolumn{2}{c}{ Late-Blinds } \\
\cline { 2 - 3 } \cline { 5 - 6 } & Guided & Prosthesis & & Gujded & Prosthesis \\
\hline Euc & 55.6 & 33.3 & & 33.3 & 11.1 \\
Non-Euc & 55.6 & 11.1 & & 22.2 & 0 \\
\hline
\end{tabular}

Pointing would have been an alternative response, but we rejected it because the consensus is that early-blind subjects never localize targets by pointing at them, except, in some conditions, for near space (Wanet \& Veraart, 1985). A board containing a pointer, such as was used by Byrne and Salter (1983) and by Dodds et al. (1982), might seem to be a more acceptable solution, but we think that, as with the drawing method, it involves processes other than those required in locomotor spatial representation. This could explain why Dodds et al. found the pointing method to be no more (and even less) precise than the drawing method. Body orientation is the initial part of a goal-oriented displacement of the body; indeed, this locomotor behavior consists of choosing a "directionally defined posture," followed by "moving activities" (Paillard, 1974). Accordingly, in our study, direction was assessed by a natural motor response; the accuracy of this quantitative measure is evidently limited, and one could assume a measurement error of a few degrees.

Because two experimental conditions were used in the present study, the problem of controlling the presentation order of these conditions had to be addressed. In our small groups of 3 blind subjects, this order could not be counterbalanced readily. Nevertheless, all blind subjects were trained to perform the task for similar routes before the experiment began; accordingly, even if a true counterbalance of the presentation order was not possible, this drawback probably was limited because of the initial training on the task. 


\section{Role of Visual Experience}

\section{in Spatial Representation}

In most studies addressing the question of the influence of visual experience in spatial representation, the spatial abilities of early-blind subjects have been found to be inferior to those of late-blind or blindfolded sighted subjects (Byrne \& Salter, 1983; Herman et al., 1983; Lockman et al., 1981; Rieser et al., 1980). Some other authors have failed to observe such differences (Juurmaa, 1967; Landau, Gleitman, \& Spelke, 1981; Samuel, 1981). Obviously, the kinds of tasks involved in these studies could account for these disparities: Such factors as length of pathway, complexity of the routes, and size of the space involved in the task must be considered. Rieser et al. (1982) emphasized the fact that the performance of earlyblind subjects more closely resembled that of blindfolded sighted subjects in an "imagination task" implying mental spatial inferences than it did in a "locomotion task" implying spatial inferences in situ. Correspondingly, in our experimental conditions (a locomotion task, according to Rieser et al., 1982), early-blind subjects were less accurate than blindfolded sighted ones, despite the shortness of our routes. Furthermore, late-blind subjects' performance did not differ from that of the sighted.

The question of why early visual experience plays a crucial role in our task arises. The results of Rieser et al. (1980) suggest that early-blind subjects might be more impaired in Euc situations than in non-Euc situations. However, we controlled this factor and failed to observe any influence of it; indeed, early-blind subjects were impaired in all aspects of the task (distance and direction), and not especially in Euc situations. However, it could be that this factor does have an influence, but that the influence is blurred by the difficulty of the task, as illustrated by the poor performance level obtained for non-Euc situations. Thus, other hypotheses must be put forward.

One hypothesis might be that, because of their use of visual imagery, visually experienced people have better spatial representation. In fact, it could be that, with visual experience, people build in their minds visual images representing a space discovered by blind movements. This classical explanation was promoted by Thomson (1980) in his study on locomotor performance with intermittent vision. However, this rationale was questioned by Dodds and Carter (1983) for a motor-memory task and by Kerr (1983) and Marmor and Zaback (1976) for mental-rotation tasks.

A second hypothesis (Dodds \& Carter, 1983) suggests that visual experience helps in the use of external cues as reference points, rather than in the building of an image of a spatial configuration. This idea agrees with Millar's (1981) conclusions about the role of visual experience: According to her, visual experience could facilitate the use of references to relations between external directions that are more obvious in vision than through the other senses and thus facilitate the use of "survey map" strategies. Such strategies could be based on computational information processing. As stressed by Millar, these strategies must not be mistaken for photographic copies and do not represent the end of a developmental progression: Early-blind people are not merely a stage behind visually experienced people. Indeed, Millar reported that some blind children used external cues as a means of reference in some experimental conditions and that, occasionally, some sighted did not. Furthermore, Rieser et al. (1980) stressed that early-blind people are able to represent space in a euclidean way in some conditions. How could this second hypothesis accommodate our results? All of our subjects performed without vision and therefore had poor external information, except for tactile exploration of landmarks and some auditory cues inside the experimental room. Accordingly, the subjects had to base their spatial representations mainly on kinesthetic and vestibular information. If this second hypothesis must account for our results, it implies that early visual experience gives the ability to create a fictive frame of reference in relation to which kinesthetic and vestibular information is coded.

A third hypothesis (Rieser et al., 1982; Warren, 1974) suggests that sighted subjects could have learned, through sensory-motor interactions, the relationships between, on the one hand, kinesthetic and vestibular information during their movements and, on the other hand, the visible effects of these movements on the network of self-to-object relations. Similarly, in his study on athletic jumps, Laurent (1981) suggested that trained people have a spatial knowledge of their stride, provided by redundant information from kinesthetic perceptions and visual effects. This hypothesis does not necessitate specific visual imagery. In agreement with Rieser et al. (1982), we further propose that, in darkness, each movement of visually experienced people would be associated with an immediate perception of the spatial relation existing between the point of departure and the position after moving. This "immediate" perception implies an information processing faster than that which occurs with a computational strategy and could be evidenced by shorter response delays. This was actually reported by Rieser et al. (1982). On the contrary, early-blind people would use computational processing and would respond after longer delays. Our experimental data do not allow verification of this assumption. Indeed, measurement of response delays in spatial assessments during the locomotion task would have been questionable because even an inexperienced subject would know the coming question during the course of the double exploration of a given route and could speculate at that time upon an adequate answer. In contrast, in another experiment in which such a strategy was precluded (the judgment position was difficult to know in advance on much longer routes), we recorded response delays significantly shorter for blindfolded, sighted children than for early-blind children (Wanet, Veraart, \& Englebienne, 1983 , and Wanet \& Veraart's unpublished results). This was demonstrated by comparing two groups of 5 subjects each in direction (Student $t=3.23, p<.01$ ) and in distance $(t=1.97, p<.05)$.

Apart from the perceptual and computational aspects of information processing, the second and third hypotheses look very similar. In addition, each mechanism implied 
by these two hypotheses would be used in the buildup of spatial representation in the absence of vision, according to early visual experience and task complexity. For example, according to the third hypothesis, visually experienced people, given knowledge of the visual consequences of their motion, could benefit from an immediate space perception in simple spatial situations. In the same situations, early-blind people could occasionally also form an accurate spatial representation, but because of the use of external cues as reference points; the related computational strategy would increase early-blinds' response times beyond those of visually experienced people. In complex situations, visually experienced people would then use strategies based on external references, and, accordingly, their response delays would be increased. In these situations, early-blind subjects generally exhibit poor performance that can be accounted for by their use of incomplete or nonadaptive strategies.

\section{Role of Electronic Travel Aids in Spatial Representation}

The ultrasonic echolocating prosthesis used in this locomotor task improved the performance of blind subjects primarily in distance assessments. This could be accounted for by the fact that, during exploration of the routes while using the ultrasonic prosthesis, the subjects could get some external feedback of the effects of their movements. This feedback could result from frequent opportunities to update their position with respect to various characteristics of the explored space (presence of a wall, nearness of a landmark, etc.). Blind people in natural conditions, of course, generally lack such external references.

The use of the ultrasonic echolocating prosthesis does not suppress performance disparities related to visual experience. One can interpret this result as the impossibility of the prosthesis to compensate for the effect of early visual deprivation on the spatial representation ability, although some improvements did occur in the early-blind subjects' performance relative to their performance without the prosthesis. Another interpretation could be that a cumulative effect of early visual deprivation played a part in these results: It could be, indeed, that the earlyblind subjects were less well trained to use the prosthesis than were the late-blind subjects. The second hypothesis can probably be ignored in light of the fact that, during and after training, early-blind and late-blind subjects reached similar performance levels in crossing a large circular field (see Method; Veraart \& Wanet, 1985); moreover, in a task of spatial localization of nearby targets, the performance of early- and late-blind subjects did not differ significantly (Veraart \& Wanet, 1985).

Improvements in distance assessments made by earlyblind subjects occurred mainly for non-Euc routes. This could support the idea that Euc situations were actually the most difficult in our locomotor task. If subjects were given more training with the prosthesis and thus more sensory-motor interactions, this new spatial information could improve localization assessments in either kind of situation.

Nevertheless, we must emphasize that spatial orientation of blind people depends not only on object localization (main purpose of the ultrasonic echolocating aid), but also on remote identification of objects. Consequently, conclusive progress in blind people's spatial representation could be achieved by combining improvements in localization and identification of objects (Veraart \& Wanet, 1985).

\section{REFERENCES}

Byrne, R. W., \& Salter, E. (1983). Distance and directions in the cognitive maps of the blind. Canadian Journal of Psychology, 37, 293-299.

CAUvin, C. (1984). Espaces cognitifs intra-urbains et cartographie non euclidienne. In J. Paillard (Ed.), La lecture sensorimotrice et cognitive de l'expérience spatiale. Paris: Centre National de la Recherche Scientifique.

Ciselet, V., Pequet, E., Richard, I., Veraart, C., \& Meulders, M. (1982). Substitution sensorielle de la vision par l'audition, au moyen de capteurs d'information spatiale. Archives Internationales de Physiologie et de Biochimie, 90, 47.

D'Hainaut, L. (1975). Concepts et méthodes de la statistique (Vol. 1). Paris: Nathan.

Dodds, A. G., \& CARTER, D. C. (1983). Memory for movement in blind children: The role of previous visual experience. Joumal of Motor Behavior, 15, 343-352.

Dodds, A. G., Howarth, C. I., \& Carter, D. C. (1982). The mental maps of the blind: The role of previous visual experience. Joumal of Visual Impairment \& Blindness, 76, 5-12.

FARMER, L. W. (1978, Fall). Mobility devices. Bulletin of Prosthetics Research, pp. 47-118.

FLETCHER, J. F. (1981). Spatial representation in blind children: 3. Effects of individual differences. Joumal of Visual Impairment \& Blindness, 75, 46-49.

FoulKe, E. (1982). Perception, cognition, and the mobility of blind pedestrians. In M. Potegal (Ed.), Spatial abilities: Development and physiological foundations. New York: Academic Press.

Gibson, J. J. (1958). Visually controlled locomotion and visual orientation in animals. British Journal of Psychology, 49, 182-194.

Gilursie, G. M., De L'Aune, W. (1974, Fall). Research at the Eastern Blind Rehabilitation Center. Bulletin of Prosthetics Research, pp. 463-468.

HABER, R. N. (1985). Understanding perceived spatial layout of scenes: A prerequisite for prostheses for blind travelers. In D. H. Warren \& E. R. Strelow (Eds.), Electronic spatial sensing for the blind. Dordrecht: Martinus Nijhoff.

HARTLAGE, L. C. (1976). Development of spatial concepts in visually deprived children. Perceptual \& Motor Skills, 42, 255-258.

Hatwell, Y. (1966). Privation sensorielle et intelligence. Paris: Presses Universitaires de France.

Herman, J. E., Chatman, S. P., \& Roth, S. F. (1983). Cognitive mapping in blind people: Acquisition of spatial relationships in a largescale environment. Journal of Visual Impairment \& Blindness, 77 , 161-166.

Hoover, R. E. (1950). The cane as a travel aid. In P. A. Zahl (Ed.), Blindness. Princeton: Princeton University Press.

Hornby, G., KAY, L., SATHERLY, M., \& KAY, N. (1985). Spatial awareness training of blind children using the trisensor. In D. H. Warren \& E. R. Strelow (Eds.), Electronic spatial sensing for the blind (pp. 257-272). Dordrecht: Martinus Nijhoff.

JANSSON, G. (1983). Tactile guidance of movement. International Journal of Neuroscience, 19, 37-46.

JUURMAA, J. (1967). Ability structure and loss of vision (Research Series No. 18). New York: American Foundation for the Blind. 
KAY, L. (1974). A sonar aid to enhance spatial perception of the blind: Engineering design and evaluation. Radio \& Electronic Engineer, 44, 605-627.

KERR, N. (1983). The role of vision in "visual imagery" experiments: Evidence from congenitally blind. Journal of Experimental Psychology: General, 112, 265-277.

Landau, B., Gleitman, H., \& Spelke, E. (1981). Spatial knowledge and geometric representation in a child blind from birth. Science, $\mathbf{2 1 3}$, $1275-1278$.

Laurent, M. (1981). Problèmes posés par l'étude du pointage locomoteur d'une cible visuelle. Cahiers de Psychologie Cognitive, 1, 173-197.

LePeCQ, J. C., \& Pêcheux, M. G. (1984). Geographical space: Spatial inferences and representations. In J. Paillard (Ed.), La lecture sensorimotrice et cognitive de l'expérience spatiale. Paris: Centre National de la Recherche Scientifique.

Lockman, J. J., Rieser, J. J., \& PICK, H. L. (1981). Assessing blind travellers' knowledge of spatial layout. Journal of Visual Impairment and Blindness, 75, 321-326.

MARMOR, G. S., \& ZabaCK, L. A. (1976). Mental rotation by the blind: Does mental rotation depend on visual imagery? Journal of Experimental Psychology: Human Perception \& Performance, 2, 514-521.

MillaR, S. (1981). Crossmodal and intersensory perception and the blind. In H. L. Pick \& R. D. Walk (Eds.), Intersensory perception and sensory integration. New York: Plenum Press.

Paillard, J. (1974). Le traitement des informations spatiales. In De l'espace corporel à l'espace écologique, Symposium de l'APSLF, P.U.F., Paris.

Rieser, J. J., Guth, D. A., \& HiLl, E. W. (1982). Mental processes mediating independent travel: Implications for orientation and mobility. Journal of Visual Impaiment \& Blindness, 76, 213-218.

RiESER, I. J., LoCKMAN, J. J., \& PICK, H. L. (1980). The role of visual experience in knowledge of spatial layout. Perception \& Psychophysics, 28, 185-190.
SAMUEL, J. M. (1981). Individual differences in the interaction of vision and proprioception. In H. L. Pick \& R. D. Walk (Eds.), Intersensory perception and sensory integration. New York: Plenum Press.

SHINGLEDECKER, C. A. (1983). Measuring the mental effort of blind mobility. Journal of Visual Impairment \& Blindness, 77, 334-339.

ShinGledecker, C. A., \& Foulke, E. (1978). A human factors approach to the assessment of the mobility of blind pedestrians. Human Factors, 20, 273-286.

Stephens, B., \& Grube, C. (1982). Development of Piagetian reasoning in congenitally blind children. Journal of Visual Impairment \& Blindness, 76, 133-143.

Thomson, J. A. (1980). How do we use visual information to control locomotion? Trends in Neurosciences, 3, 247-250.

VeraART, C., \& Wanet, M.-C. (1985). Sensory substitution of vision by audition. In D. H. Warren \& E. R. Strelow (Eds.), Electronic spatial sensing for the blind (pp. 217-238). Dordrecht: Martinus Nijhoff.

Wanet, M.-C., \& VeraarT, C. (1985). Processing of auditory information by the blind in spatial localization tasks. Perception \& Psychophysics, 38, 91-96.

Wanet, M.-C., Veraart, C., \& Englebienne, B. (1983). Contribution of sensory substitution to space perception by the blind. Archives Internationales de Physiologie et de Biochimie, 91, 76-77.

Warnath, C., \& Seyfarth, G. J. (1982). Guide dogs-mobility tool and social bridge to the sighted world. Journal of Rehabilitation, 48, 58-61.

WARREN, D. H. (1974). Early vs. late vision: The role of early vision in spatial reference systems. New Outlook for the Blind, 2, 93-94.

(Manuscript received June 2, 1986; revision accepted for publication February 24, 1987.) 